\title{
Article \\ Enhanced Nitrite Detection by a Carbon Screen Printed Electrode Modified with Photochemically-Made AuNPs
}

\author{
Malak Talbi ${ }^{1,2, *(D)}$, Ammar Al-Hamry ${ }^{1}$ (D), Priscila Rios Teixeira ${ }^{3}$, Leonardo G. Paterno ${ }^{3}$, Mounir Ben Ali ${ }^{2,4}$ \\ and Olfa Kanoun ${ }^{1}$ (iD
}

check for

updates

Citation: Talbi, M.; Al-Hamry, A.;

Teixeira, P.R.; Paterno, L.G.; Ali, M.B.; Kanoun, O. Enhanced Nitrite Detection by a Carbon Screen Printed Electrode Modified with

Photochemically-Made AuNPs.

Chemosensors 2022, 10, 40. https://

doi.org/10.3390/

chemosensors 10020040

Academic Editor: Danila Moscone

Received: 23 December 2021

Accepted: 19 January 2022

Published: 22 January 2022

Publisher's Note: MDPI stays neutral with regard to jurisdictional claims in published maps and institutional affiliations.

Copyright: (C) 2022 by the authors. Licensee MDPI, Basel, Switzerland. This article is an open access article distributed under the terms and conditions of the Creative Commons Attribution (CC BY) license (https:// creativecommons.org/licenses/by/ $4.0 /)$
1 Measurement and Sensor Technology, Technische Universität Chemnitz, Reichenhainer Straße 70, 09126 Chemnitz, Germany; ammar.al-hamry@etit.tu-chemnitz.de (A.A.-H.); olfa.kanoun@etit.tu-chemnitz.de (O.K.)

2 NANOMISENE Lab, LR16CRMN01, Centre for Research on Microelectronics and Nanotechnology of Sousse, University of Sousse, Sousse 4034, Tunisia; mounir.benali@issatso.rnu.tn

3 Laboratório de Pesquisa em Polímerose Nanomateriais, Instituto de Química, Universidade de Brasília, Brasilia DF 70297-400, Brazil; priscilariost@gmail.com (P.R.T.); lpaterno@unb.br (L.G.P.)

4 Electronic Department, University of Sousse, Higher Institute of Applied Science and Technology of Sousse, Sousse 4003, Tunisia

* Correspondence: malak.talbi@etit.tu-chemnitz.de

\begin{abstract}
Excessive nitrite amounts harm the environment and put public health at high risk. Therefore, accurate and sensitive detection of nitrite in surface and groundwater is mandatory for mitigating its adverse effects. Herein, a highly sensitive electrochemical sensor based on carbon screen-printed electrodes (CSPE) surface-modified with photochemically-made gold nanoparticles (AuNPs, 12 nm) is proposed for nitrite detection. Scanning electron microscopy, cyclic voltammetry, and electrochemical impedance spectroscopy show that AuNPs uniformly coat the CSPE, increase its surface area, and contribute to oxidizing nitrite to much lower potential (+0.5 V vs. $\mathrm{Ag} / \mathrm{AgCl})$ and faster rate. Under optimized differential pulse voltammetry conditions, the CSPE/AuNPs-PEI electrode responds linearly $\left(R^{2}>0.99\right)$ to nitrite within a wide concentration range $(0.01-4.0 \mu \mathrm{M})$, showing a sensitivity of $0.85 \mu \mathrm{A} \cdot \mu \mathrm{M}^{-1} \cdot \mathrm{cm}^{-2}$ and limit of detection as low as $2.5 \mathrm{nM}$. The CSPE/AuNPs-PEI electrode successfully detects nitrite in tap water and canned water of olives, showing no influence of those matrices. In addition, the electrode's response is highly reproducible since a relative standard deviation lower than $10 \%$ is observed when the same electrode is operated in five consecutive measurements or when electrodes of different fabrication batches are evaluated.
\end{abstract}

Keywords: nitrite detection; gold nanoparticles; carbon screen-printed electrode; differential pulse voltammetry; electrochemical impedance spectroscopy

\section{Introduction}

The excessive use of chemical fertilizers, the heavy use of pesticides in farming and industrial activities, and household waste have resulted in high levels of pollutants in the environment. Thus, the uncontrolled rise in the level of contamination affects the quality of drinking water, draining aquatic ecosystems and damaging the ecological cycle. Nitrite $\left(\mathrm{NO}_{2}^{-}\right)$is one of the most common inorganic nitrogenous compounds found in the environment and is widely used as a food additive and preservative [1], as well as nitrogenbased fertilizers utilized in agriculture [2,3]. Nonetheless, nitrite has been classified as a hazardous species due to its toxicity to humans. The excess intake of nitrite can accelerate the irreversible oxidation reaction of hemoglobin to methemoglobin, thus limiting the ability of hemoglobin to carry oxygen [4]. Besides that, nitrite may react with amines to form nitrosamines, which are toxic and carcinogenic [5]. For these reasons, the allowable limit of nitrite concentration in drinking water is $43.48 \mu \mathrm{M}$, according to the World Health Organization (WHO) guidelines [1]. It is, therefore, of great urgency, the development of fast, sensitive, and reliable methods for nitrite detection. 
So far, a variety of approaches exists for nitrite detection, such as spectrophotometry [6,7], chromatography [8,9], and chemiluminescence [10]. However, most of them have many disadvantages, such as toxic chemicals, reagents, complicated and high-cost equipment, time-consuming sample preparation, low selectivity, and inability to perform on-site monitoring. Conversely, electrochemical sensors have been considered as relevant alternatives because they ensure a rapid, sensitive, and low-cost method for the determination of nitrites [11-14]. Moreover, electrochemical sensors can be fabricated as miniaturized devices, allowing for on-site monitoring of nitrite by non-skilled personnel. Nevertheless, it is still challenging to improve sensitivity and other performance parameters for electrochemical sensing of nitrite.

For electrochemical sensors, both sensitivity and selectivity to a specific target species are very important. One of the main causes of low sensitivity can be due to adsorption of interfering substances on the electrode surface, which reduces the efficiency of the reactions and leads therefore to measurement deviations. Therefore, the sensor loses sensitivity and even specificity to the target species [15]. Additionally, the effective modification of the electrode surface by the effective nanomaterials should achieve selective and sensitive binding of the target species [16]. By using nanomaterials, like incorporating carbon nanomaterials or metal nanoparticles into a working electrode [17], an increase of the surface area and/or conductivity of the electrode can be reached leading to an increase of the sensitivity and signal level. A highly sensitive sensor having a low LOD is essential. It is also important that it reaches the required sensitivity level for a particular application.

In that regard, significant efforts have been devoted to improving these performance parameters, which have been focused on the functionalization of different electrodes with nanomaterials [18]. Recently, interest has been focused on metal and metal oxide nanoparticles (M-NPs and MO-NPs) and their widespread application in analytical chemistry for displaying unique physicochemical properties owing to their enlarged surface-to-volume ratio [19]. Many of these nanoparticles have been employed in nitrite electrochemical sensors, including silver [20], copper [21], platinum [22] and iron oxide [23] nanoparticles, and mainly gold nanoparticles (AuNPs).

AuNPs display very attractive properties, such as electrocatalytic activity, good electrical conductivity, chemical stability, and appropriate biocompatibility, which are very attractive for building electrochemical sensors [24]. In addition, AuNPs can be synthesized at controlled size and shape and assembled into organized thin films employing mild experimental conditions [25]. These distinctive features make AuNPs a promising nanomaterial, and as a result, many research studies based on AuNPs have proven the excellent effect for the electrocatalytic oxidation of nitrite [14,26-31].

For example, Abbas et al. [26] prepared a carbon paste electrode modified with AuNPs multi-walled carbon nanotubes nanocomposite (AuNPs/MWCPE) to determine nitrite. Hanbing et al. [27] developed an electrochemical sensing platform based on the deposition of AuNps on chitosan@N, S co-doped multi-walled carbon nanotubes composite modified glassy carbon electrode (GCE). Huaiyin Chen et al. [28] elaborated a nitrite sensor based on a copper metal-organic framework decorated with AuNPs (Cu-MOF/Au/GCE). Furthermore, Shenghong et al. [29] modified $\alpha-\mathrm{Fe}_{2} \mathrm{O}_{3}$ nanorods with AuNPs giving rise to AuNPs- $\mathrm{Fe}_{2} \mathrm{O}_{3}$ composite that was effectively used as photoelectrode to detect nitrite. Hao Yu et al. [30] detected nitrite by preparing an AuNPs-reduced graphene oxide and multiwalled carbon nanotubes (AuNP/rGO/MWCNTs) nanocomposite. Paramasivian et al. [31] reported the synthesis of $\beta$-cyclodextrin capped AuNPs ( $\beta$-CD@AuNPs) without the use of additional reducing agents. $\beta-C D$ molecules act as reducing agents and stabilizers, and no hazardous reagents or conditions have been used. In addition, $\mathrm{Xin} \mathrm{Li} \mathrm{et} \mathrm{al.} \mathrm{reported}$ in [32] about the process of the electrodeposition of gold nanoparticles on a glassy carbon electrode (GCE) functionalized with $\mathrm{MoS}_{2}$ nanosheets, which showed a good response for sodium nitrite under optimal conditions.

This study reports about the use of AuNPs, produced by an ecofriendly photochemical route, to modify commercially available carbon screen-printed electrodes (CSPE) and use 
them on the sensitive detection of nitrite. Moreover, it is observed that the CSPE/AuNPsPEI electrode's response to nitrite is insensitive to different tested matrices, such as tap water and canned water of olives, thereby demonstrating its promising use in real applications. The structure and morphology of AuNPs and CSPE/AuNPs-PEI are fully assessed by UV-Vis spectroscopy and high-resolution microscopy (transmission electron microscopy, TEM, and scanning electron microscopy, SEM). The effect of AuNPs electrode modification is further investigated by cyclic voltammetry and electrochemical impedance spectroscopy. The sensing performance is evaluated by differential pulse voltammetry. In general, a sample fabrication process proposed herein is capable to achieve a very sensitive level with good reproducibility, and a very low limit of detection.

\section{Materials and Methods}

\subsection{Apparatus and Chemicals}

Carbon screen-printed electrodes (Itasens IS-C) were purchased from PalmSens BV, Houten, Netherlands. PalmSens 3 potentiostat (PalmSens BV, Houten, Netherlands) was used in all experimental measurements. The $\mathrm{pH}$ measurements were carried out using a $\mathrm{pH}$ meter (model TM 39) with a combined $\mathrm{pH}$ glass and temperature electrode (Sensortechnik Meinsberg $\mathrm{GmbH}$, Germany). Analytical grade chloroauric acid $\left(\mathrm{HAuCl}_{4} \cdot 3 \mathrm{H}_{2} \mathrm{O}\right)$, branched poly(ethyleneimine) (PEI, $\left.\mathrm{M}_{\mathrm{W}} 60,000 \mathrm{~g} \mathrm{~mol}^{-1}\right)$, sodium nitrite $\left(\mathrm{NaNO}_{2}\right)$, potassium ferrocyanide $\left(\mathrm{K}_{4}\left[\mathrm{Fe}(\mathrm{CN})_{6}\right]\right)$, potassium ferricyanide $\left(\mathrm{K}_{3}\left[\mathrm{Fe}(\mathrm{CN})_{6}\right]\right)$, sodium phosphate monobasic monohydrate $\left(\mathrm{NaH}_{2} \mathrm{PO}_{4} \cdot \mathrm{H}_{2} \mathrm{O}\right)$, and sodium phosphate dibasic heptahydrate $\left(\mathrm{Na}_{2} \mathrm{HPO}_{4} \cdot 7 \mathrm{H}_{2} \mathrm{O}\right)$ were used, respectively, for standard nitrite solutions, ferri/ferrocyanide redox probe solution and phosphate buffer solution (PBS) are purchased from SigmaAldrich without any further purification. For interference measurements, $\mathrm{MgCl}_{2}, \mathrm{MgSO}_{4}$, $\mathrm{CaCl}_{2}, \mathrm{NaOH}, \mathrm{KCl}, \mathrm{NaNO}_{3}, \mathrm{Na}_{2} \mathrm{SO}_{4}, \mathrm{NaBr}$, ascorbic acid, uric acid were used. All chemicals were of analytical grade, purchased from Sigma-Aldrich Germany, and applied in this study as received without further purification or refinement.

\subsection{Synthesis of AuNPs and Characterization}

AuNPs were produced by a photochemical method as described elsewhere [33]. In brief, $5 \mathrm{~mL}$ of aqueous $\mathrm{HAuCl}_{4} \cdot 3 \mathrm{H}_{2} \mathrm{O}$ solution $\left(0.88 \mathrm{mmol} \mathrm{L}^{-1}\right)$ and $10 \mathrm{~mL}$ of PEI solution $\left(1.0 \mathrm{~g} \cdot \mathrm{L}^{-1}\right)$ were mixed in a $25 \mathrm{~mL}$ borosilicate beaker and then exposed for $30 \mathrm{~min}$ to UV irradiation $(254 \mathrm{~nm}, 16 \mathrm{~W})$ inside a lab-made reaction chamber as depicted in [26]. The obtained suspension was stored in the fridge $\left(\sim 8^{\circ} \mathrm{C}\right)$ until structural characterizations and electrode modification. Herein, PEI is employed to ensure the colloidal stability of AuNPs.

For structural and morphological characterizations, UV-Vis spectra of AuNPs were recorded in an Agilent Cary 8454 UV-Visible spectrophotometer, Agilent technologies,

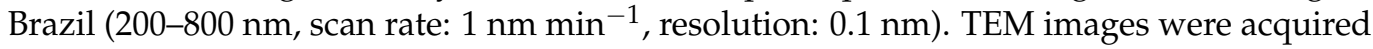
with a JEOL JEM-1011 (JEOL, Japan) microscope, whereas hydrodynamic diameter and zeta potential were assessed with the Malvern Zeta Sizer Nano ZS (Malvern Panalytical, Brazil). SEM and EDX spectra of electrodes were recorded with Nova NanoSEM 200 microscope (Thermo Fisher, Germany).

\subsection{Electrode Preparation and Preliminary Nitrite Investigations}

CSPE modification was achieved by drop-casting of AuNPs suspension onto the central, working electrode and then dried at room temperature. Different volumes of AuNPs suspensions (2-10 $\mu \mathrm{L})$ were evaluated to optimize the modification of the electrode. The highest obtained nitrite oxidation current is at $6 \mu \mathrm{L}$ in $0.1 \mathrm{M}$ of PBS and $0.001 \mathrm{M}$ of nitrite, as shown in Figure $1 b$. 


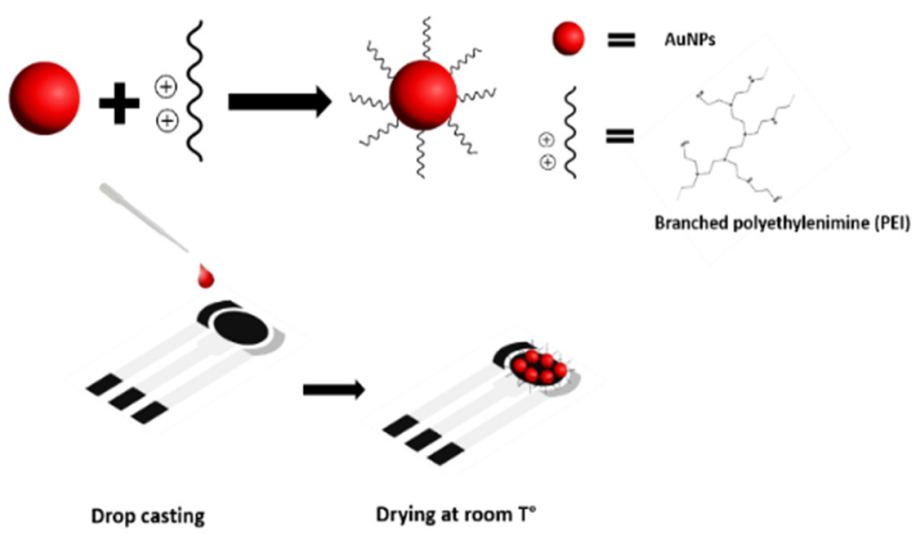

(a)

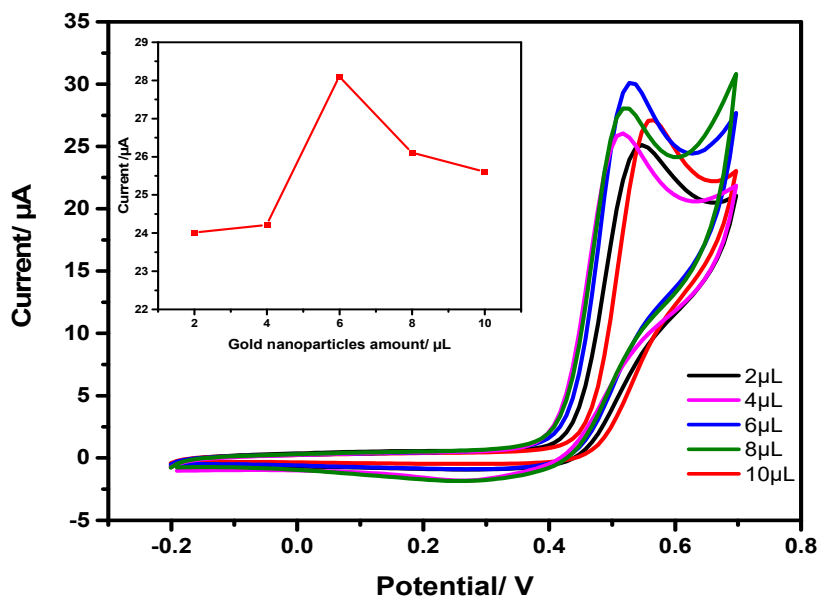

(b)

Figure 1. (a) Electrode functionalization with gold nanoparticles; (b) Cyclic voltammograms of different amounts of AuNPs solution deposition and optimization with inset plot of gold nanoparticle amount as a function of oxidation current of nitrite in $0.1 \mathrm{M}$ of PBS and $0.001 \mathrm{M}$ of nitrite.

PBS buffer solutions were prepared with distilled water and a concentration of $0.1 \mathrm{M}$ at different $\mathrm{pH}$ levels and ambient room temperature for all experiments. For primary electrode investigations, these buffers are added to $0.5 \mathrm{mM}$ of Ferri/ferrocyanide redox probe in $0.5 \mathrm{mM}$ of $\mathrm{KCl}$ and then running cyclic voltammetry (with a scan rate of $5 \mathrm{mV} / \mathrm{s}$ ) and electrochemical impedance spectroscopy measurements (at the frequency range $0.01 \mathrm{~Hz}$ to $300 \mathrm{~Hz}, 12$ points per decade and $0.5 \mathrm{~V}$ amplitude). For impedance data fitting, the Circuit Fitting option was used in the PSTrace 5.5 software. After that, optimizing working conditions in DPV for nitrite detection and preparing different nitrite solutions in the concentration range of $1000 \mu \mathrm{M}$ to $0.001 \mu \mathrm{M}$ were carried out. The interference study was investigated in the absence and presence of a 100 fold excess of different interfering species such as $\mathrm{Na}^{+}, \mathrm{NO}_{3}^{-}, \mathrm{Br}^{-}, \mathrm{K}^{+}, \mathrm{Cl}^{-}, \mathrm{Ca}^{2+}, \mathrm{NH}_{4}^{+}, \mathrm{HPO}_{4}^{2-}$ and $\mathrm{SO}_{4}^{2-}$. Furthermore, a real test was done with tap water and caning olives water samples spiked with $0.001 \mathrm{M}$ of nitrite.

\section{Results and Discussion}

\subsection{Structural and Morphological Characterization of AuNPs and CSPE/AuNPs-PEI}

The main structural feature of the AuNPs suspension is the plasmonic band centered at $530 \mathrm{~nm}$. The size distribution histogram displayed in Figure 2a provides a mean diameter of $12.9 \pm 0.4 \mathrm{~nm}$, after fitting experimental data with a log-normal function. The hydrodynamic diameter is about four times greater, $55.5 \pm 0.5 \mathrm{~nm}$, thus revealing the adsorption of PEI onto AuNPs. Indeed, this is confirmed further by the positive zeta potential equal to $+26.0 \pm 2.3 \mathrm{mV}$, which is ascribed to positively charged amine and imine groups [34].

In addition, TEM images in Figure $2 \mathrm{~b}$ reveal a sphere-like shape and the crystalline planes pointing towards the (111) direction, as shown by the inset. The interplanar distance highlighted in yellow is $0.268 \mathrm{~nm}$, which gives a lattice parameter of $0.44 \mathrm{~nm}$. This value is compatible with that expected for FCC gold $(0.406 \mathrm{~nm})$ [35].

The chemical composition and structural morphology of the CSPE/ AuNPs-PEI were analyzed by SEM. From Figure 3a, the structure of the graphite flakes is observed at a 40,000 times magnification (scale bar of $3.0 \mu \mathrm{m}$ ). In addition, Figure 3b, shows well-defined spherical gold nanoparticles are distributed evenly on the top of the electrode. Few of them are accumulated heavily in different areas of the working electrode surface. Figure $3 c, d$ show the EDX spectra for the elemental composition characterization of the bare and modified electrode that proves the electrode's modification with gold. 


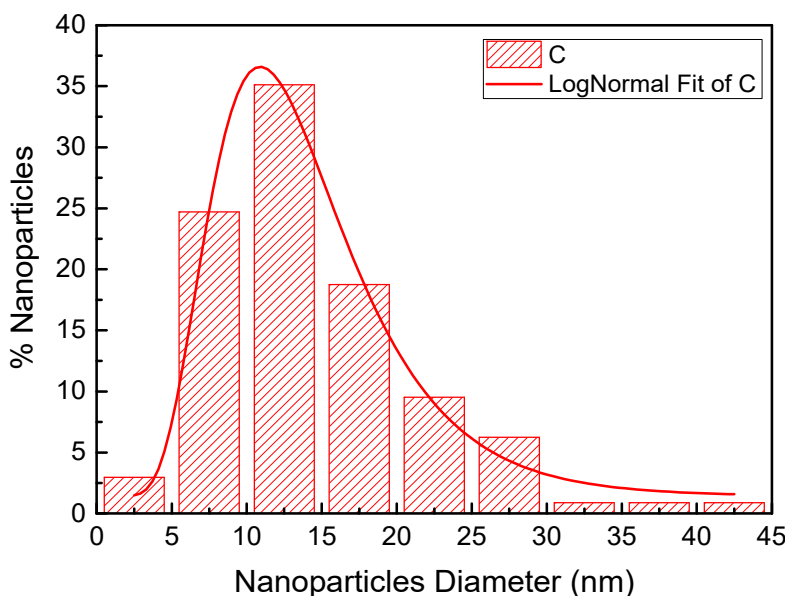

(a)

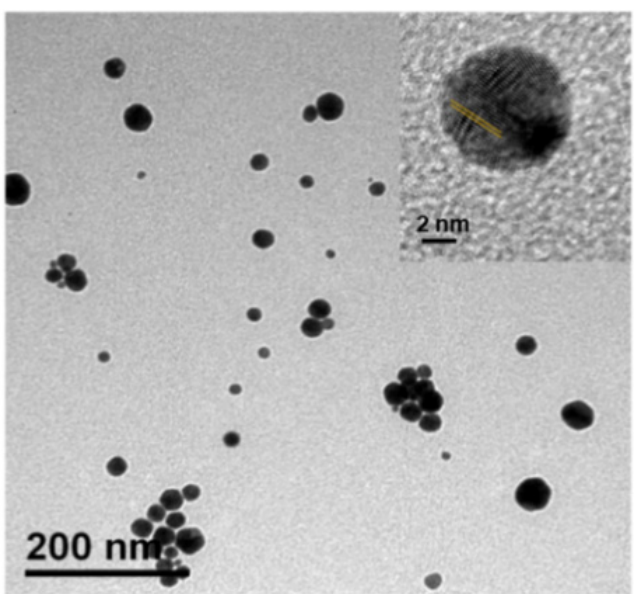

(b)

Figure 2. (a) Histogram of the size distribution of AuNPs; (b) Transmission electron microscopy (TEM) images of AuNPs.

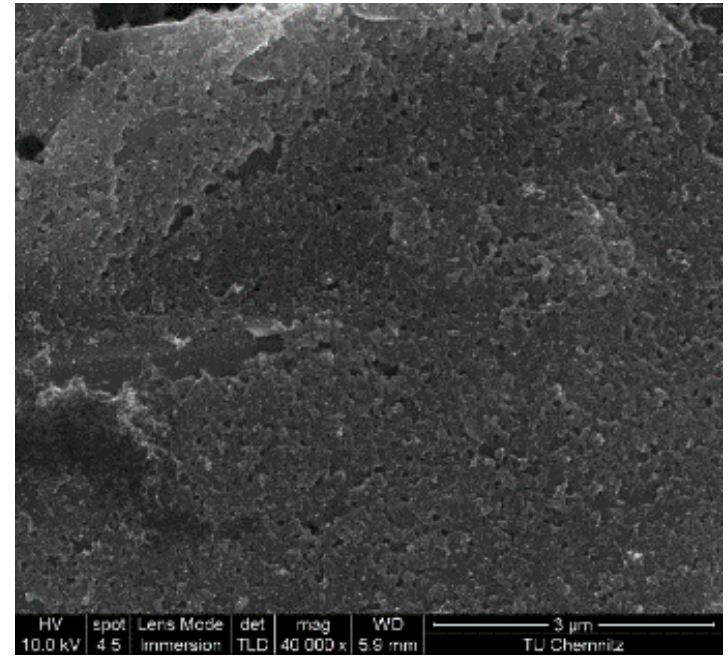

(a)

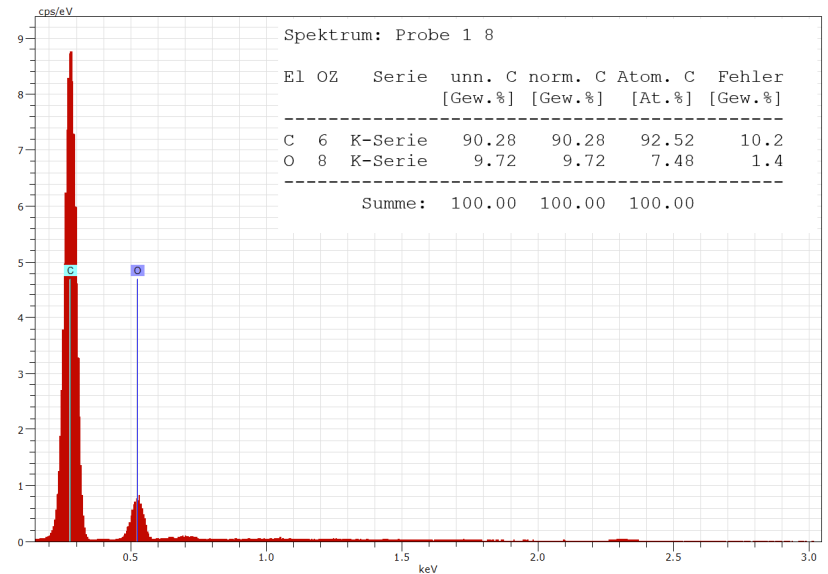

(c)

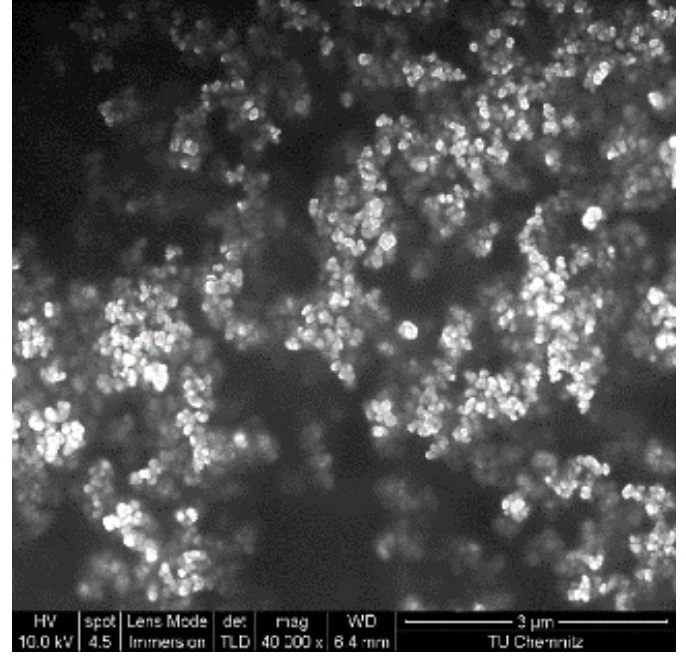

(b)

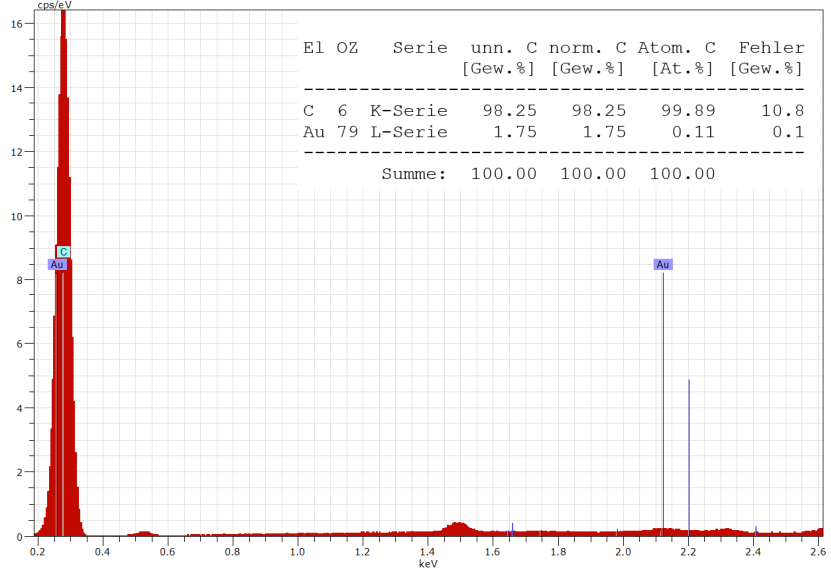

(d)

Figure 3. SEM images of (a) bare; (b) modified SPE with AuNPs. EDS spectrums of the (c) bare; (d) modified electrodes with inset tables for different elemental compositions. 


\subsection{Electrochemical Behaviour of CSPE/AuNPs-PEI Modified Electrode}

The electrochemical behaviour of CPSE/AuNPs-PEI has been first investigated in a ferri/ferrocyanide redox couple by $\mathrm{CV}$ and EIS. Figure 4a,b show cyclic voltammograms in ferri/ferrocyanide (with $5 \mathrm{mM}$ of $\mathrm{KCl}$ ) registered at different scan rates $\left(20-200 \mathrm{mV} \mathrm{s}^{-1}\right.$ ) with bare CSPE and CSPE/AuNPs, respectively.

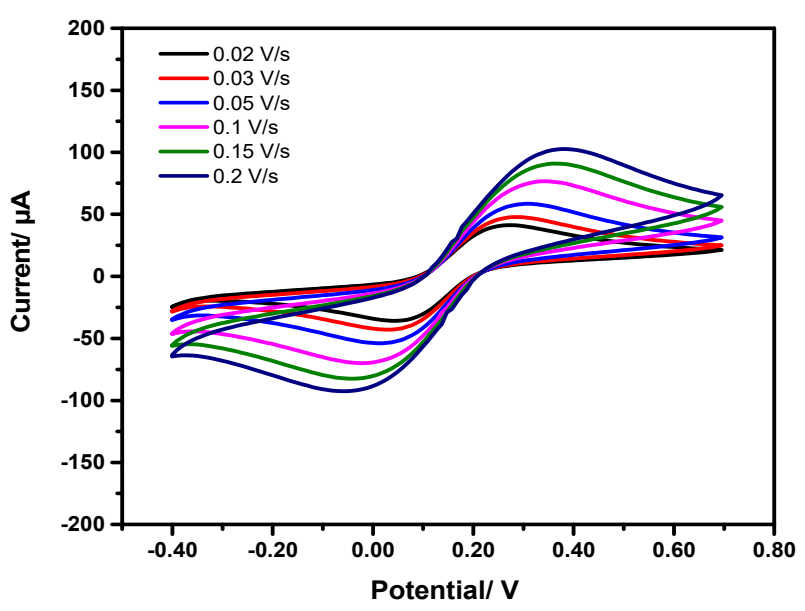

(a)

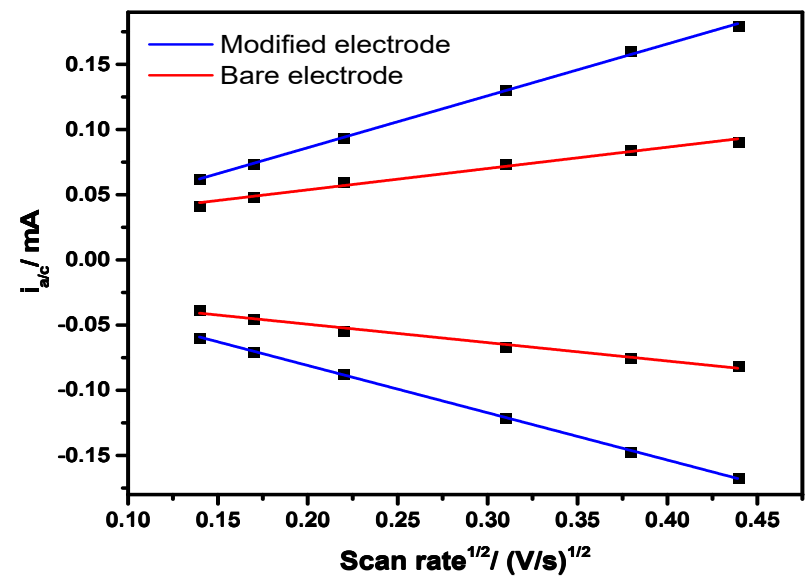

(c)

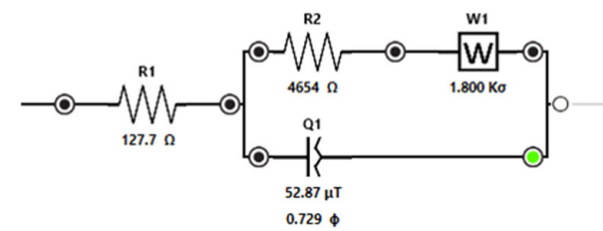

Circuit 1

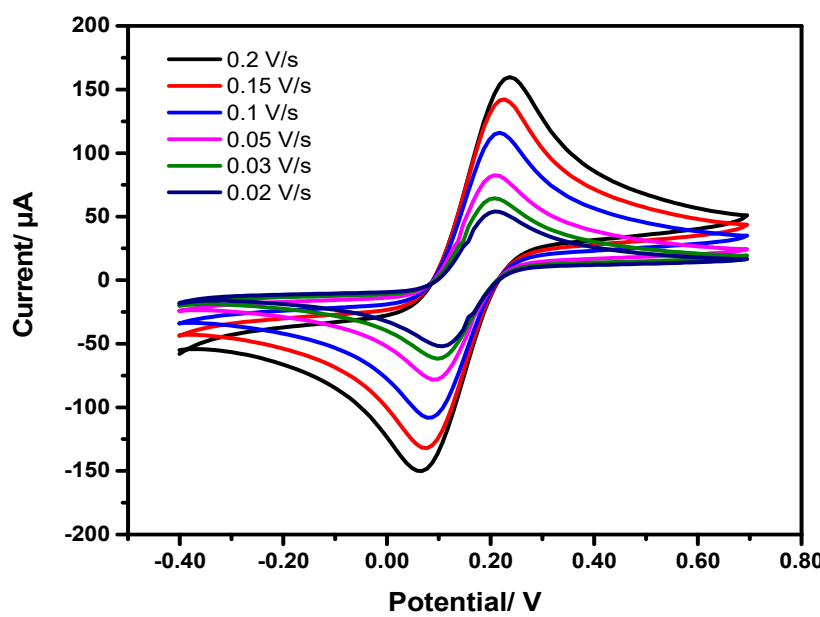

(b)

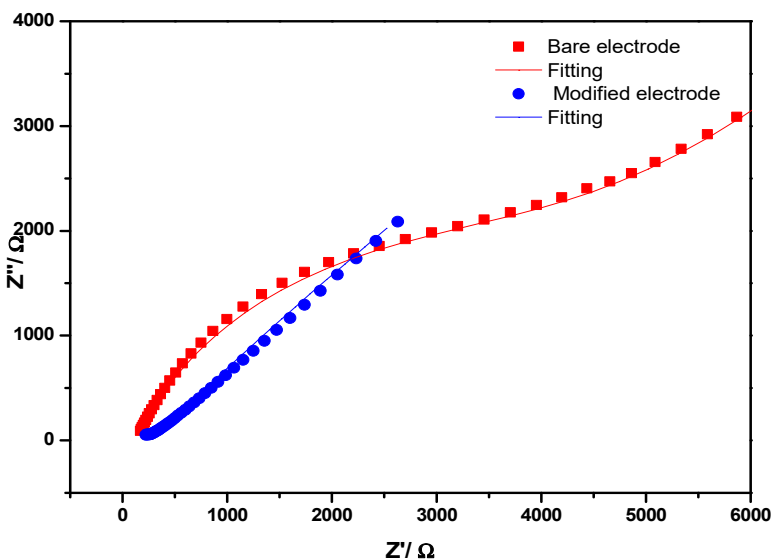

(d)

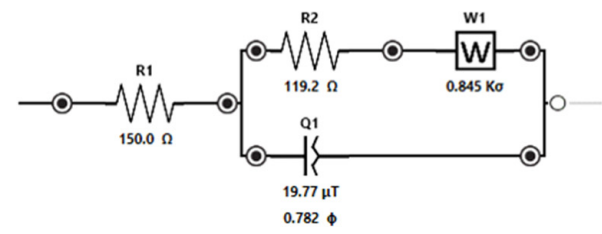

Circuit 2

(e)

Figure 4. Electrochemical response to $[\mathrm{Fe}(\mathrm{CN}) 6]^{3-/ 4-}$ (in $5 \mathrm{Mm} \mathrm{KCl}$ ): Cyclic voltammograms registered at different scan rates using; (a) bare electrode CPSE and; (b) CSPE/AuNPs; (c) relation of anodic/cathodic peak currents as a function of the square root of the scan rate; and (d) impedance spectra of bare electrode CPSE and CSPE/AuNPs-PEI; (e) equivalent circuits of bare and modified CSPE from fitted spectra.

Although the $\left[\mathrm{Fe}(\mathrm{CN})_{6}\right]^{3-} \leftrightarrow\left[\mathrm{Fe}(\mathrm{CN})_{6}\right]^{4-}$ oxidation-reduction occurs for both electrodes, the effect of modification by AuNPs is apparent. For example, at $200 \mathrm{mV} \mathrm{s}^{-1}$, the peak-to-peak separation $\Delta \mathrm{Ep}=\left(E p_{o x}-E p_{\text {red }}\right)$ is $191 \mathrm{mV}$, and the anodic peak current is 
$100 \mu \mathrm{A}$ for bare CSPE, whereas for CSPE/AuNPs-PEI these values are $100 \mathrm{mV}$ and $150 \mu \mathrm{A}$, respectively. It means that the $\left[\mathrm{Fe}(\mathrm{CN})_{6}\right]^{3-} \leftrightarrow\left[\mathrm{Fe}(\mathrm{CN})_{6}\right]^{4-}$ reaction is more favorable and becomes quasi-reversible upon AuNPs modification.

The anodic/cathodic peak currents were then plotted versus the square root of the scan rate, as shown in Figure 4c. There is a linear relationship between them, confirming a diffusion-controlled process. Besides that, the slope is greater with the CSPE/AuNPs-PEI, indicating that AuNPs increase the electroactive area of bare CSPE. Indeed, the estimated electroactive area of bare and AuNPs modified CSPE is $0.07 \mathrm{~cm}^{2}$ and $0.11 \mathrm{~cm}^{2}$, respectively. In addition, EIS spectra (Nyquist plots) shown in Figure $4 \mathrm{~d}$ provide even stronger evidence for the beneficial effect of AuNPs on the electrochemical performance of CSPE. After curve fitting, the experimental data with the equivalent circuit of $R_{S-}\left(\left[R_{C T}-W|| C_{P E}\right]\right.$, in Figure $4 \mathrm{e}$, circuit 1 and circuit 2 represent the Randle circuit for the bare and modified electrode, respectively. The charge-transfer resistance $\left(\mathrm{R}_{\mathrm{CT}}\right)$ estimated for CSPE is $4654 \Omega$, and it is steeply decreased to $119.2 \Omega$ for CSPE/AuNPs-PEI. Therefore, it is concluded that modification with AuNPs enlarges the electroactive area, consequently reducing the charge-transfer resistance at the electrode/electrolyte interface. Besides that, it can be hypothesized that positively charged PEI coating the AuNPs favours the adsorption of anionic $[\mathrm{Fe}(\mathrm{CN}) 6]^{3-/ 4-}$, which contributes further to the enhanced electrochemical signal.

\subsection{Electrocatalytic Activity of CSPE/AuNPs-PEI towards Nitrite Oxidation}

As an electroactive ion, nitrite has two possible mechanisms for its electrochemical detection: oxidation or reduction. The most commonly used detection way is the oxidation of nitrite since its reduction is quite complicated, and it can involve several interferences such as nitrate ions and the reduction of molecular oxygen [36,37].

The nitrite electro-oxidation process typically involves the following Equations [30]:

$$
\begin{gathered}
\mathrm{NO}_{2}^{-} \leftrightarrow \mathrm{NO}_{2}+\mathrm{e}^{-} \\
2 \mathrm{NO}_{2}+\mathrm{H}_{2} \mathrm{O} \leftrightarrow \mathrm{NO}_{3}^{-}+2 \mathrm{H}^{+}
\end{gathered}
$$

At first, nitrite ions get oxidized at the electrode surface to $\mathrm{NO}_{2}^{-}$, and secondly, the $\mathrm{NO}_{2}^{-}$is homogeneously processed in a second-order disproportionation process to generate nitrate ions. In the case where the scan rate is slow, the whole process occurring at the electrode could be described by Equation (3):

$$
\mathrm{NO}_{2}^{-}+\mathrm{H}_{2} \mathrm{O} \leftrightarrow \mathrm{NO}_{3}^{-}+2 \mathrm{H}^{+}+2 \mathrm{e}^{-}
$$

Nevertheless, when the scan rate is high, it is unlikely that the homogeneous protonation of $\mathrm{NO}_{2}^{-}$occurs, and in this case, the reaction described in Equation (1) is the prevalent one by which one electron is transferred [30].

Figure 5 shows cyclic voltammograms and EIS spectra of $\mathrm{NO}_{2}^{-}(1 \mathrm{mM}$ in PBS pH 7) registered with bare CSPE and CSPE/AuNPs-PEI. In Figure 5a, the voltammograms clearly show an anodic peak, corresponding to $\mathrm{NO}_{2}^{-}$oxidation (reaction 1) [26], which occurs at lower potential $(+0.57 \mathrm{~V})$ and higher current (approximately doubled value) at CSPE/AuNPs-PEI. In Figure 5b, the EIS spectra indicate a significant impedance decrease upon modification of bare CSPE with AuNPs. After fitting the experimental data with an $R_{S-}\left(\left[R_{C T-} W|| C_{P E}\right]\right.$ equivalent circuit, values of $R_{C T}$ were determined; $5400 \Omega$ for bare CSPE and $600 \Omega$ for CSPE/AuNPs-PEI. It is seen that AuNPs reduce $R_{C T}$, thereby causing a decrease in the onset oxidation potential and increase of the anodic current for the $\mathrm{NO}_{2}^{-}$oxidation.

This decrease reduces the rate of electron transfer at the electrode interface. The effect of the $\mathrm{pH}$ on the electrochemical response of CSPE/AuNPs-PEI to nitrite was investigated with CV. As shown in Figure 6, the maximum peak current was reached at $\mathrm{pH}$ 6.5. However, the peak current decreases at $\mathrm{pH}$ lower or higher than 6.5. Therefore, $\mathrm{pH} 6.5$ was chosen for further studies. According to some reports, at low pHs (lower than 4), protonation 
of nitrite will occur, forming nitrous acid, $\mathrm{HNO}_{2}[32,33]$. This will affect the electrode's response, explaining the low current measured at $\mathrm{pH}<5$. Conversely, at a more basic $\mathrm{pH}$, oxidation of AuNPs is expected to occur, which will form a passivating oxide layer that prevents nitrite oxidation and adversely affects the stability of the electrode $[26,38,39]$.

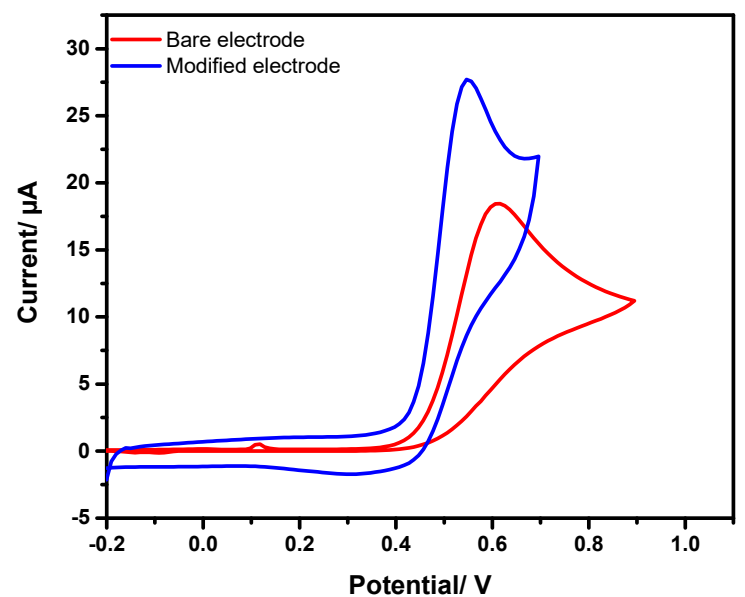

(a)

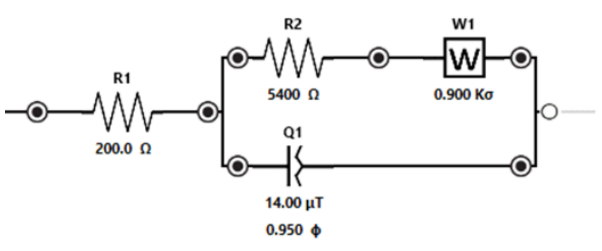

Circuit 1

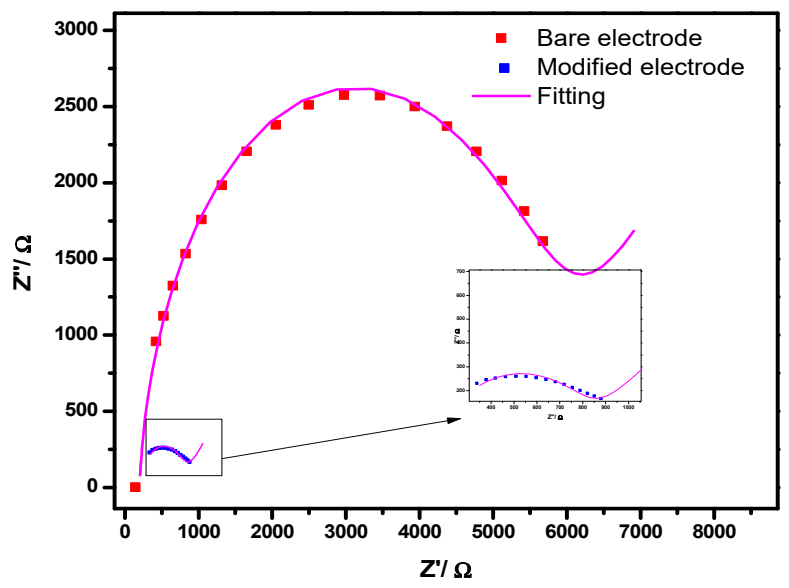

(b)

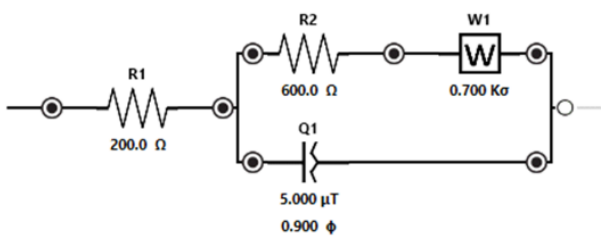

Circuit 2

(c)

Figure 5. Study of nitrite oxidation reaction in $1 \mathrm{mM}$ of $\mathrm{NaNO}_{2}$ and $0.1 \mathrm{M}$ of $\mathrm{PBS}$ buffer at $\mathrm{pH}=7$ on bare and modified electrode with AuNPs-PEI with; (a) cyclic voltammograms; (b) electrochemical impedance spectroscopy spectra; (c) and equivalent circuits for bare (cuicuit1) and modified electrode (cuicuit2).

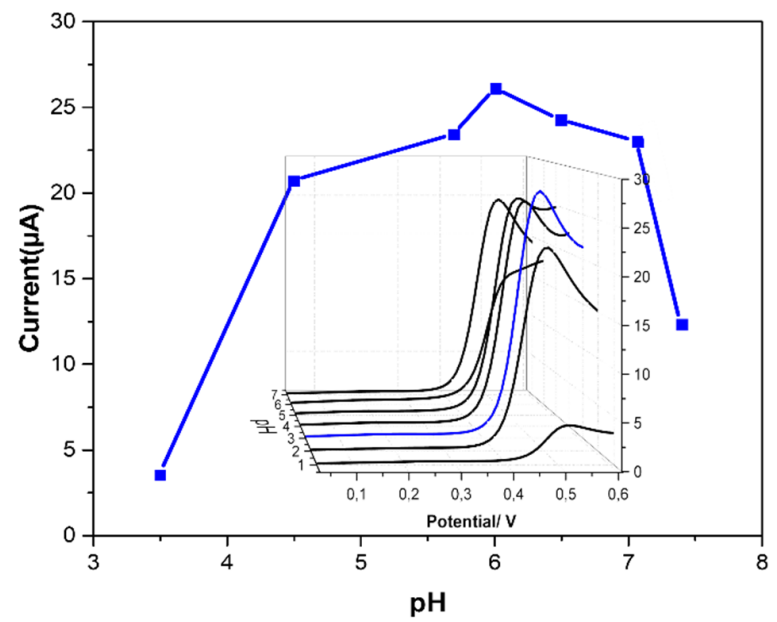

Figure 6. $\mathrm{pH}$ study of the modified electrode with AuNPs in $1 \mathrm{mM}$ of $\mathrm{NaNO}_{2}$ and $0.1 \mathrm{M}$ of $\mathrm{PBS}$ buffer at different $\mathrm{pH}$ values; relation between nitrite oxidation peak currents as a function of the oxidation potential with inset of cyclic voltammograms of nitrite oxidation currents.

The electrochemical kinetics of nitrite oxidation at the CSPE/AuNPs-PEI electrode was investigated by $\mathrm{CV}$, and in Figure 7 the results are shown. Figure $7 \mathrm{a}$ illustrates 
cyclic voltammograms of nitrite oxidation performed at different scan rates in $0.1 \mathrm{M}$ of PBS solution at $\mathrm{pH} 6.5$ and in the potential range between $-0.2 \mathrm{~V}$ and $0.7 \mathrm{~V}$. The nitrite oxidation is evidenced by an anodic peak around $+0.57 \mathrm{~V}$, which shifts to more anodic potentials as the scan rate increases, suggesting an irreversible process. In Figure $7 \mathrm{~b}$, a linear dependence between the anodic current and the square root of the scan rate is observed, which indicates a diffusion-controlled process.

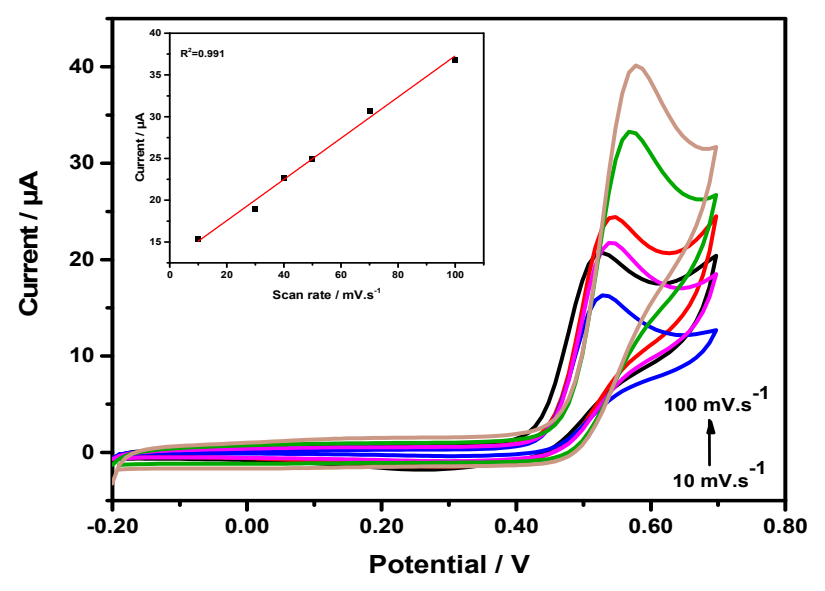

(a)

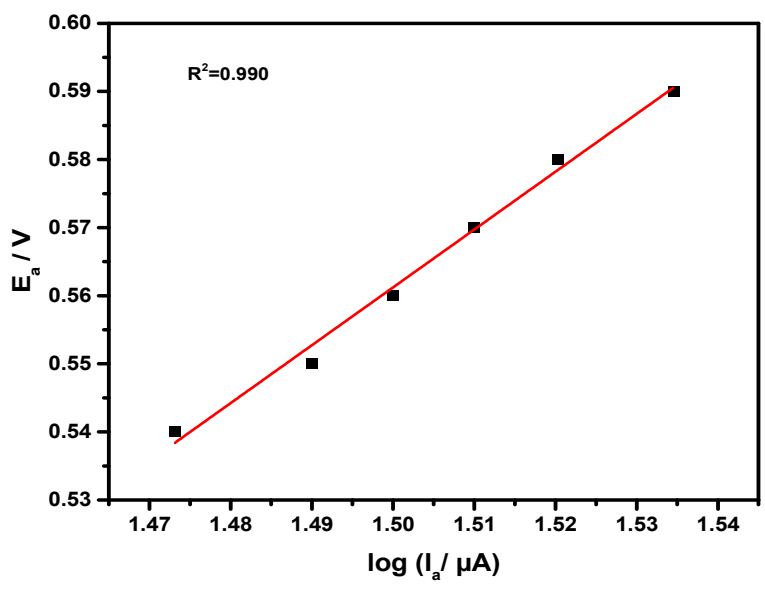

(c)

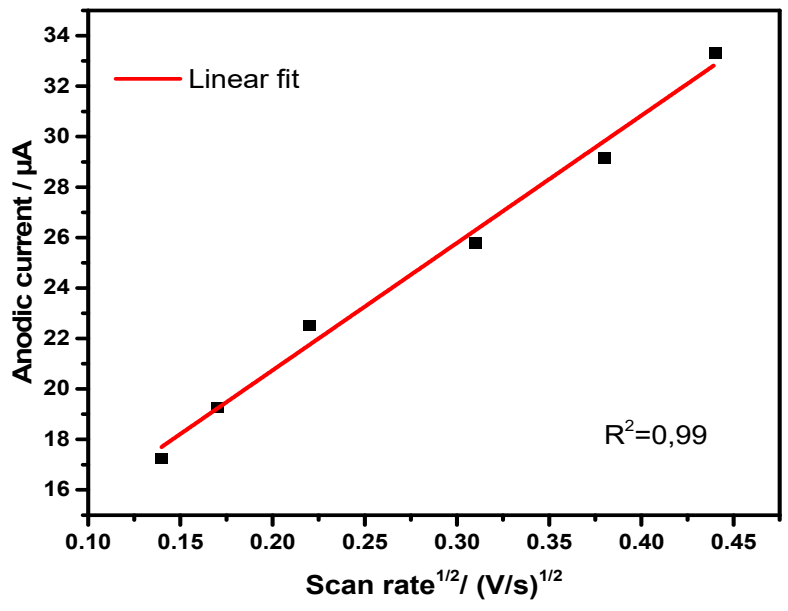

(b)

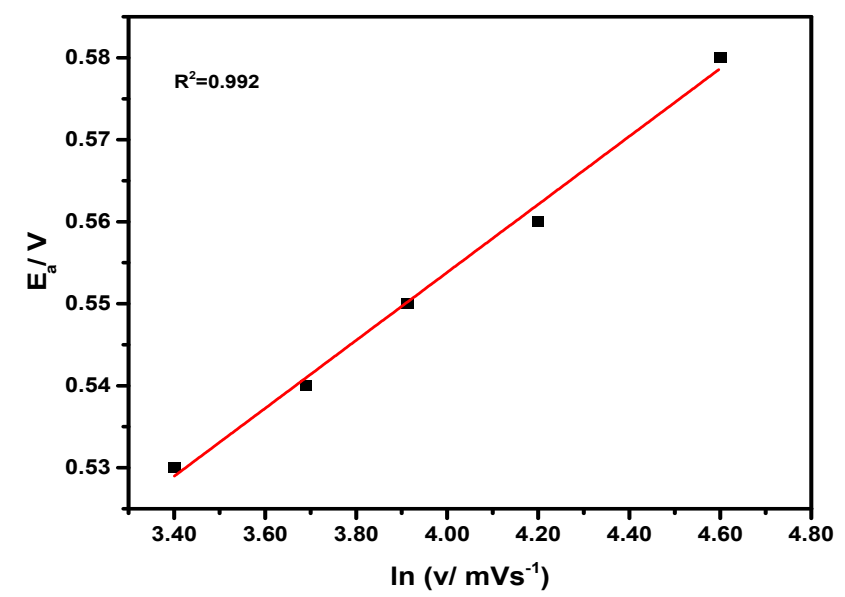

(d)

Figure 7. (a) Cyclic voltammograms of nitrite oxidation at different scan rates values in which the inset is the linear dependency of the scan rate and anodic current; (b) variation of the square root of the scan rate as a function of anodic oxidation current of nitrite; (c)Tafel's plot of nitrite oxidation at $50 \mathrm{mV} / \mathrm{s}$; (d) dependence of peak potential $\left(\mathrm{E}_{\mathrm{a}}\right)$ on $\ln \mathrm{v}$.

The Tafel plot is provided in Figure $7 c$, described by the linear equation $E_{a}=0.85 x-0.714$ $\left(R^{2}=0.990\right)$, where $E_{a}$ represents the overpotential of nitrite oxidation. The slope of this equation relates to the charge-transfer coefficient $\alpha$ through Equation (4):

$$
0.85=\frac{2.303 R T}{(1-\alpha) \mathrm{F}}
$$

where $\mathrm{R}$ is the gas constant (8.31 J.K.mol $\left.{ }^{-1}\right), \mathrm{T}$ is the absolute temperature $(298 \mathrm{~K})$, and $\mathrm{F}$ is the faraday constant $\left(96,500 \mathrm{C} \cdot \mathrm{mol}^{-1}\right)$. The value of $\alpha$ calculated from that is 0.93 . The dependence of the anodic peak potential on $\ln v$ is provided in Figure $7 d$, which gives a 
linear relationship: $E_{\mathrm{pa}}=0.387+0.041 \ln v\left(\mathrm{R}^{2}=0.992\right)$. Since the reaction is irreversible and diffusion-controlled, $E_{\mathrm{pa}}$ and $\ln v$ are related by Equation (5):

$$
E_{\mathrm{pa}}=\left(\frac{\mathrm{RT}}{2 \alpha \mathrm{n}_{\alpha} \mathrm{F}}\right) \ln \mathrm{v}+\mathrm{const}
$$

in which $\mathrm{n}_{\alpha}$ is the number of transfer electrons. The value found for $\mathrm{n}_{\alpha}$ is 0.33 .

\subsection{Electrochemical Determination of Nitrite}

After obtaining qualitative data on the oxidation process and a good electrochemical response in cyclic voltammetry measurements, the investigation was carried out to develop the analytical method for detecting nitrite in an aqueous solution. Differential pulse voltammetry (DPV) technique was applied to record the signals. Under optimum conditions $\left(\mathrm{E}_{\text {pulse }}=0.1 \mathrm{~V}, \mathrm{t}_{\text {pulse }}=0.01 \mathrm{~s}\right.$ and scan rate of $\left.0.05 \mathrm{~V} / \mathrm{s}\right)$, voltammograms illustrated in Figure 8a show the performance of CSPE/AuNPs-PEI in 0.1 M of PBS (pH 6.5) under different concentrations of nitrite, ranging from 10 to $400 \mathrm{nM}$ at $50 \mathrm{mV} / \mathrm{s}$ scan rate. As expected, the increase of the nitrite concentration is accompanied by an increase in the oxidation peak current.

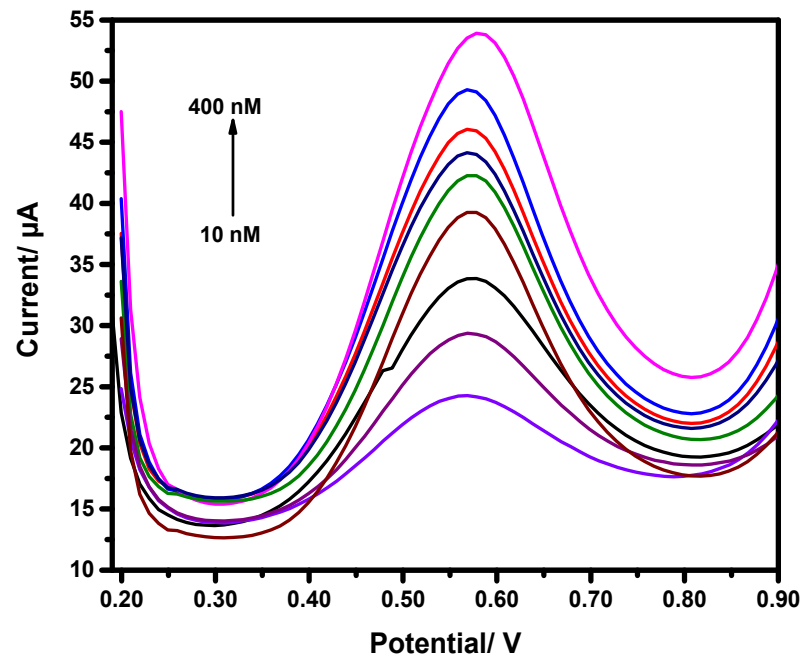

(a)

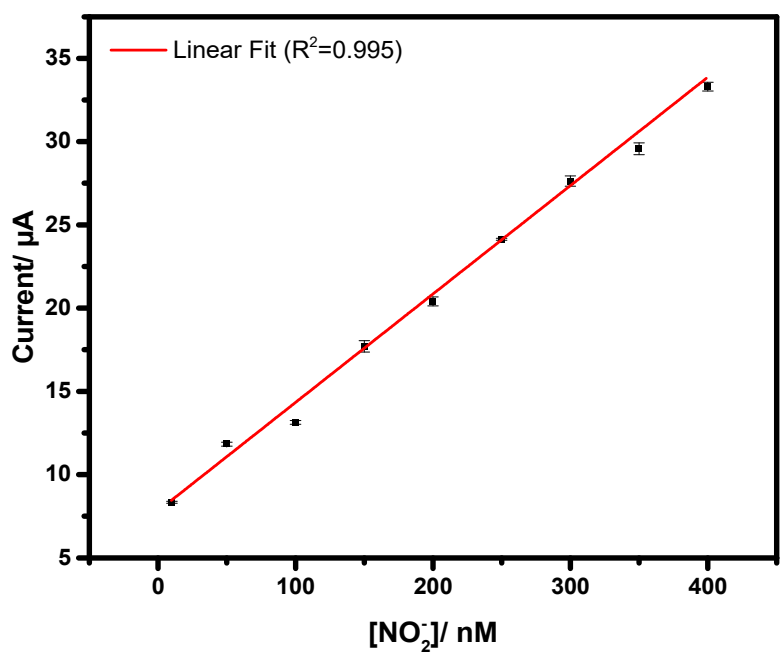

(b)

Figure 8. (a) Differential pulse voltammograms responses of CSPE/AuNPs-PEI in different concentrations of nitrite in $0.1 \mathrm{M}$ of PBS at $\mathrm{pH} 6.5$ and $50 \mathrm{mV} / \mathrm{s}$ scan rate; (b) Calibration curve of nitrite detection in the concentration range of 10 to $400 \mathrm{nM}$.

In Figure $8 \mathrm{~b}$, the dependency of the oxidation peak current on the nitrite concentration is provided. From this analytical curve (concentration of $\mathrm{NO}_{2}^{-}$vs. current response), which is fitted with a linear correlation, it is observed that the peak current increases linearly with the increase of nitrite concentration.

The linear regression equation $(\mathrm{y}(\mu \mathrm{A})=0.065 \mathrm{x}(\mathrm{nM})+7.71)$ was acquired with a high correlation coefficient $\mathrm{R}^{2}=0.995$. The sensor's sensitivity towards $\mathrm{NO}_{2}^{-}$was found to be at least $0.065 \mu \mathrm{A} / \mathrm{nM}$, and it shows a limit of detection (LOD) of $2.5 \mathrm{nM}$ for a signal-tonoise ratio of 3 . The achieved electrocatalytic performances of the CSPE/AuNPs-PEI were compared to other nitrite sensors reported in the literature based on different nanomaterials, as shown in Table 1. 
Table 1. Sensing performances comparisons of previously reported nitrite sensors with different nanomaterials.

\begin{tabular}{|c|c|c|c|c|c|}
\hline Electrode & Technique & $\begin{array}{c}\text { Linear Range } \\
(\mu \mathrm{M})\end{array}$ & $\begin{array}{c}\text { Sensitivity } \\
\mu \mathrm{A} \cdot \mu \mathrm{M}^{-1} \cdot \mathrm{cm}^{-2}\end{array}$ & LOD $(\mu \mathrm{M})$ & Ref. \\
\hline AuNPs/rGO a /MWCNTs ${ }^{b}$ & Amperometry & $0.05-2200$ & 1.201 & 0.014 & {$[30]$} \\
\hline ERGO $^{c} /$ AuNPs & DPV & $1-6000$ & 0.3048 & 0.13 & [40] \\
\hline $\mathrm{AuNPs}-\mathrm{Fe}_{2} \mathrm{O}_{3} \mathrm{~d}$ & $\mathrm{CV}$ & $1-1000$ & $0.149 \pm 0.01$ & 0.07 & [29] \\
\hline AuNPs/MoS2 e /Gr & Amperometry & $5-5000$ & - & 1 & [41] \\
\hline $\mathrm{Au} / \mathrm{ERGO} / \mathrm{CuTDPAT}$ f/GCE & Amperometry/DPV & $0.001-1000$ & - & 0.006 & {$[42]$} \\
\hline$\beta-C D @ A u N P s$ g $/ G C E$ & Amperometry & $0.04-1470$ & - & 0.014 & [31] \\
\hline Dendrimer/AuNPs-I/GC & Amperometry & $10-5000$ & 0.640 & 0.2 & [43] \\
\hline $\mathrm{RGO} / \mathrm{MnFe}_{2} \mathrm{O}_{4} \mathrm{~h} / \mathrm{PANI}$ & Amperometry & $0.05-12,000$ & - & 0.015 & [37] \\
\hline AuNPs/Ti3C2Tx-PDDA ${ }^{i}$ & Amperometry & $\begin{array}{c}0.1-2490 \text { and } \\
2490-13,490\end{array}$ & 0.250 & 0.059 & [1] \\
\hline $\mathrm{Fe} 3 \mathrm{O} 4{ }^{\mathrm{j}} / \mathrm{GO} / \mathrm{COOH} / \mathrm{GC}$ & DPV & $90-600$ & 2.17 & 0.37 & [44] \\
\hline CSPE/AuNPs-PEI & DPV & $0.01-4$ & 0.85 & 0.0025 & This work \\
\hline
\end{tabular}

${ }^{\mathrm{a}}$ Reduced Graphene oxide $/{ }^{\mathrm{b}}$ Multiwalled carbon nanotubes $/{ }^{\mathrm{c}}$ Electrochemically reduced graphene oxide/ d $\mathrm{Fe}_{2} \mathrm{O}_{3}$ : Iron oxide/e Molybdenum disulfide nanoflower $/{ }^{\mathrm{f}}$ Copper-based metal-organic framework/ $\mathrm{g} \beta$-Cyclodextrin Capped Gold Nanoparticles $/{ }^{\mathrm{h}}$ Manganese ferrite $/{ }^{\mathrm{i}}$ poly (dimethyl diallyl ammonium chloride)decorated MXene/j: Iron oxide black.

It can be noted that the present sensor exhibits excellent figures of merit in terms of having a higher sensitivity and a lower limit of detection. These results suggest that the CSPE/AuNPs-PEI electrode can be successfully used as a sensor for $\mathrm{NO}_{2}^{-}$. The performance of the proposed sensor for the determination of nitrite ions has been investigated under the presence of possibly interfering species that usually coexist with $\mathrm{NaNO}_{2}$. As shown in Figure 9, anionic and cationic species i.e., $\mathrm{Na}^{+}, \mathrm{NO}^{3-}, \mathrm{Br}^{-}, \mathrm{K}^{+}, \mathrm{Cl}^{-}, \mathrm{Ca}^{2+}, \mathrm{NH}_{4}^{+}, \mathrm{HPO}_{4}^{2-}$ and $\mathrm{SO}_{4}^{2-}$ were tested. The DPV experiments were carried out with nitrite at $1 \mathrm{mM}$, in the absence and the presence of each interfering species at 100-fold excess. Unlike the apparent current increase with $\mathrm{NaNO}_{2}$ injection, the current changes caused by the addition of most interferants were negligible, indicating the good selectivity of $\mathrm{NaNO}_{2}$ with the developed sensor. An exception has to be made for $\mathrm{NH}_{4} \mathrm{Cl}$, in which the interfering effect can be as high as $30 \%$. For that specific interfering species, an additional calibration curve should be prepared to address this effect. Generally, chloride ions in water are noticeable in the millimolar range, and nitrite ions in the micromolar range. Consequently, chloride ions may interfere in the direct detection of nitrite in water samples. Chloride can precipitate $\mathrm{AgCl}$ along with $\mathrm{AgNO}_{3}$, thus $\mathrm{Cl}^{-}$interference could be avoided by the addition of a suitable amount of $\mathrm{AgNO}_{3}$ to water samples. Furthermore, $\mathrm{AgNO}_{3}$ can precipitate other interfering ions such as $\mathrm{Br}^{-}$, which improves the sensor's selectivity [30].

\subsection{Analytical Study}

Nitrite always remains in the environment and is a common additive in salty food products. To evaluate the performance of the proposed sensor for practical application for nitrite detection in real samples, the CSPE/AuNPs-PEI electrode was tested in mineral water and canning water of olives. These measurements were conducted with no primary preparation. In addition, the samples were spiked with $0.001 \mathrm{M}$ of $\mathrm{NaNO}_{2}$. DPV voltammograms in Figure 10 show the response to nitrite in both mineral water (Figure 10a) and canning water of olives (Figure 10b) before and after nitrite addition, which proves that the application of the sensor in real samples is practical. 


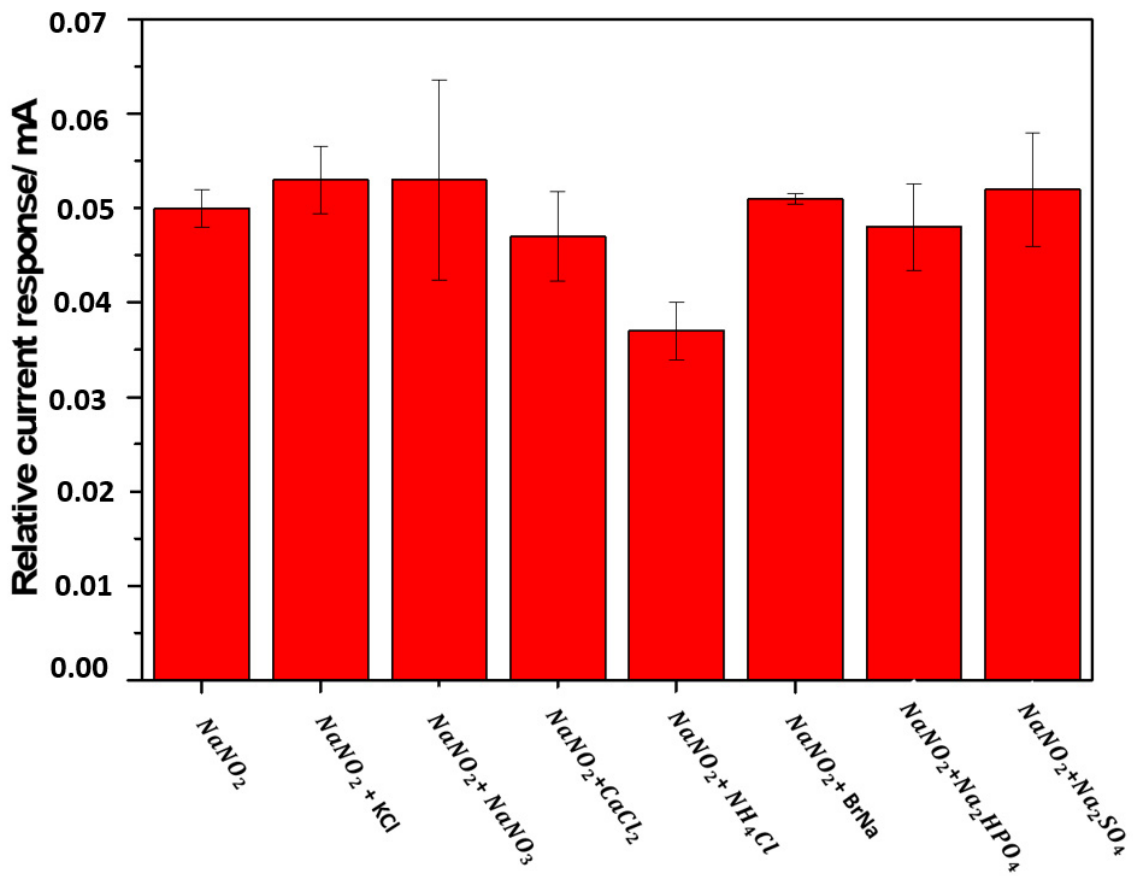

Figure 9. Influence of different chemical compounds on the oxidation current of nitrite; error bars indicate the standard deviations of 3 repeated tests.

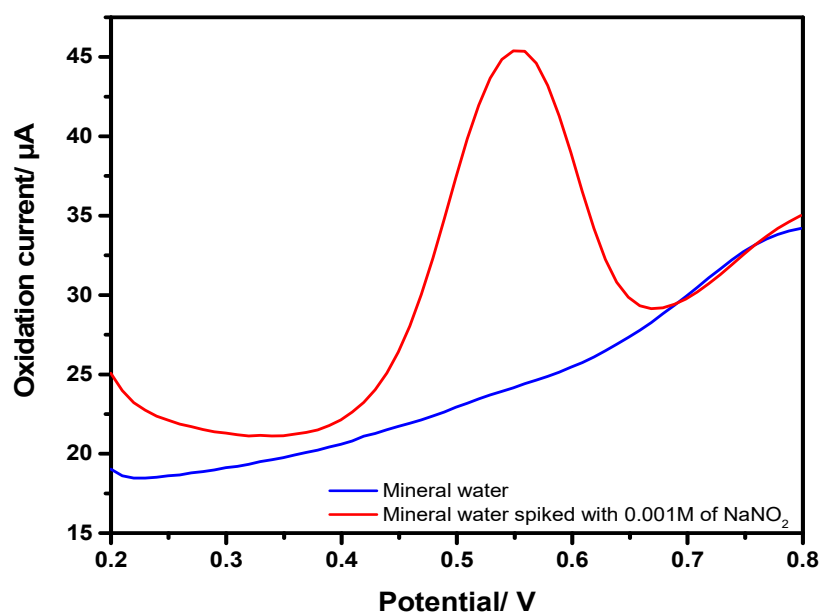

(a)

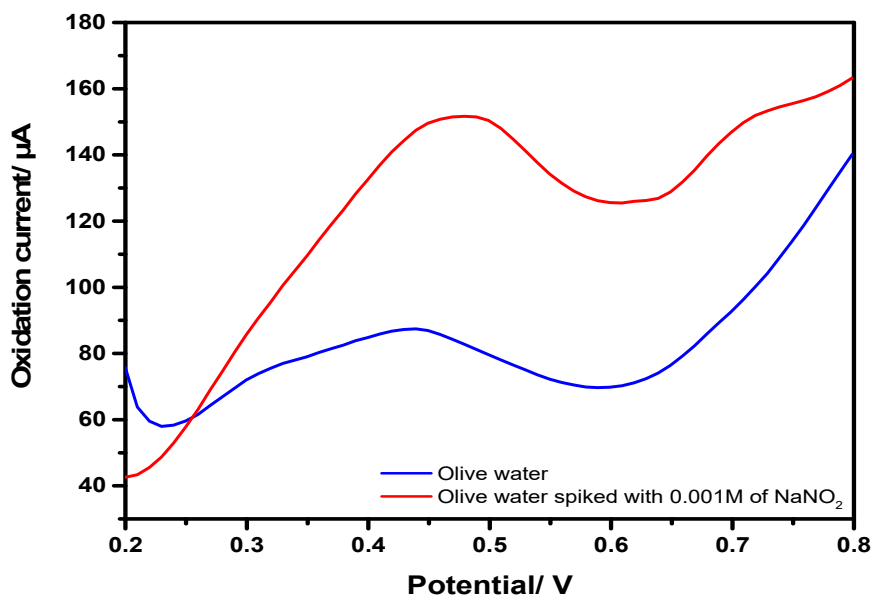

(b)

Figure 10. Differential pulse voltammograms of nitrite oxidation in; (a) mineral water and; (b) olive water spiked with $0.001 \mathrm{M}$ of nitrite, respectively.

\subsection{Reproducibility and Stability}

In order to access the reproducibility of the sensor's response, DPV curves were first registered with a single CSPE/AuNPs-PEI electrode in five consecutive measurements in nitrite concentration of $0.001 \mathrm{M}$ with $0.1 \mathrm{M}$ of PBS solution at $\mathrm{pH}$ 6.5. As shown in Figure 11a, the shape of DPV curves and respective current signals remain stable after running the five consecutive measurements. Second, an intra-study, as illustrated in Figure 11b, based on testing five different electrodes fabricated under identical experimental conditions, shows an RSD lower than $10 \%$. Accordingly, the suggested sensor has a good reproducibility for nitrite measurement. 


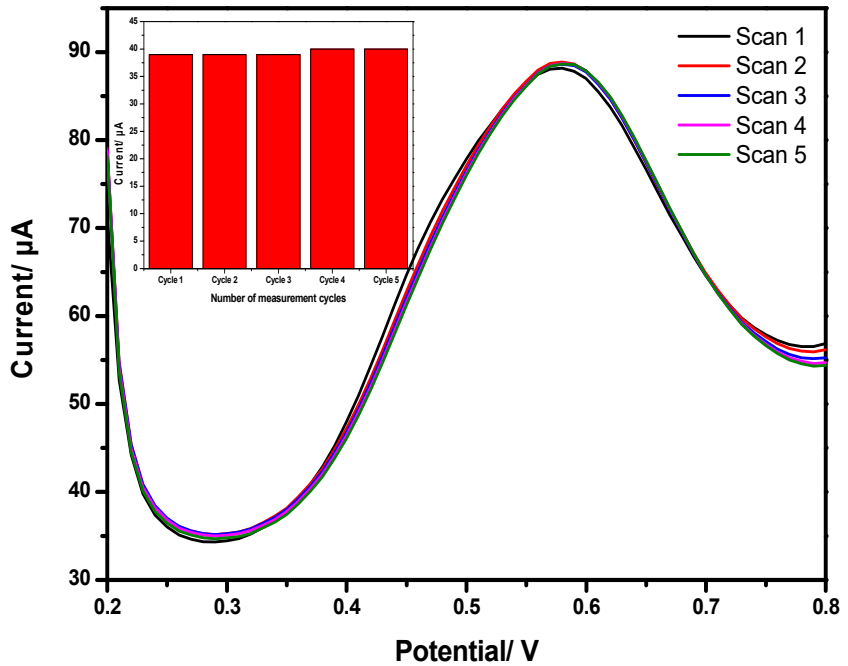

(a)

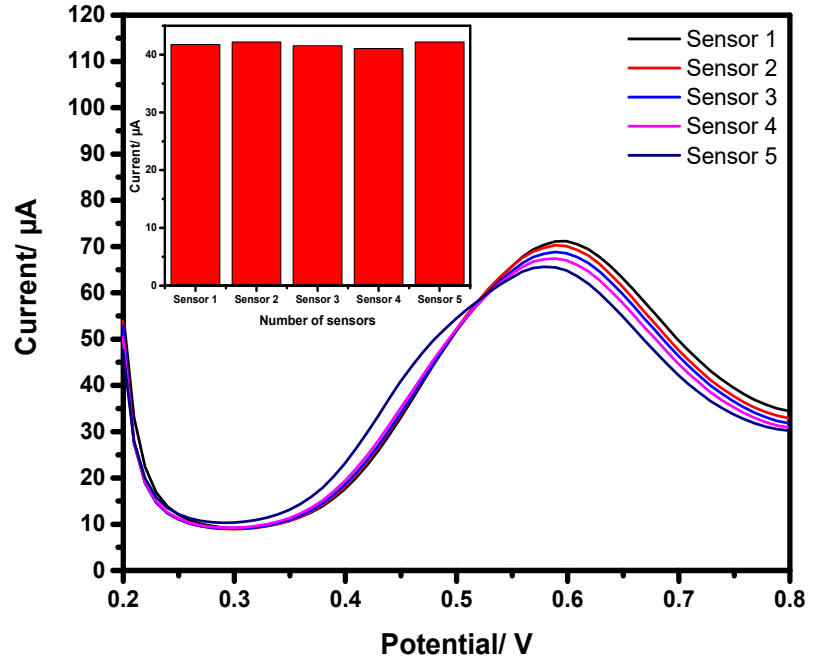

(b)

Figure 11. Reproducibility investigation of the electrode in $0.001 \mathrm{M}$ of nitrite with $0.1 \mathrm{M}$ of PBS ( $\mathrm{pH}$ 6.5); (a) inter-study and; (b) intra-study.

\section{Conclusions}

This study demonstrates that photochemically-synthesized gold nanoparticles coated with poly(ethyleneimine) provide a strong electrocatalytic effect for commercially available carbon screen-printed electrodes toward nitrite oxidation. The improved performance of the proposed modified electrode is ascribed to the enlarged electroactive area provided by gold nanoparticles and electrostatic attraction promoted by positively charged poly(ethyleneimine). This synergistic effect is responsible for detecting nitrite at very low potential $(+0.57 \mathrm{~V})$ and obtaining a very low limit of detection $(2.5 \mathrm{nM})$, the latter being among the lowest found in the literature. In addition, the sensor exhibited good sensitivity and selectivity and is insensitive to different matrices. Since the production of these gold nanoparticles is accomplished by a photochemical process that does not require hazardous reagents, the proposed nitrite sensor is environmentally friendly and, therefore, very promising for determining nitrite in real samples.

Author Contributions: M.T., O.K., M.B.A. and A.A.-H., conceptualization; M.T., P.R.T., formal analysis; M.T., investigation, data processing, writing and preparation of original draft; L.G.P., A.A.-H., M.B.A. and O.K., writing-revision and editing; O.K., A.A.-H., project administration. All authors have read and agreed to the published version of the manuscript.

Funding: This research was funded by NutriCon funded by the Sächsische Aufbaubank (SAB), grant number 24119201. Furthermore, the authors acknowledge the financial support within the project Nitramon project funded by the Sächsische Aufbaubank (SAB) and the European Social Fund (ESF), grant number 100339427. O.K. and A.A.-H. acknowledge the financial support by Deutsche Forschungsgemeinschaft (DFG) (PhotoSens project no. KA 1663/12-1). O.K. acknowledges the financial support by Deutsche Forschungsgemeinschaft (DFG) (DualSens project no. KA 1663/13-1).

Acknowledgments: The authors acknowledge the support of Aleksandr Oshchepkov (within the project Nitramon) from Technische Universität Chemnitz (chemical department), group of Supramolecular Chemistry for solutions preparation and discussions. We thank Christoph Tegenkamp and Doreen Dentel from the Institute of Physics (Solid Surfaces Analysis) for the access to scanning electron microscope (SEM) imaging.

Conflicts of Interest: The authors declare no conflict of interest. The funders had no role in the design of the study; in the collection, analyses, or interpretation of data; in the writing of the manuscript, or in the decision to publish the results. 


\section{References}

1. Wang, Y.; Zeng, Z.; Qiao, J.; Dong, S.; Liang, Q.; Shao, S. Ultrasensitive determination of nitrite based on electrochemical platform of AuNPs deposited on PDDA-modified MXene nanosheets. Talanta 2021, 221, 121605. [CrossRef]

2. Kanoun, O.; Lazarević-Pašti, T.; Pašti, I.; Nasraoui, S.; Talbi, M.; Brahem, A.; Adiraju, A.; Sheremet, E.; Rodriguez, R.D.; Ali, M.B.; et al. A review of nanocomposite-modified electrochemical sensors for water quality monitoring. Sensors 2021, 21, 4131. [CrossRef] [PubMed]

3. Han, S.; Chen, X. Copper nanoclusters-enhanced chemiluminescence for folic acid and nitrite detection. Spectrochim. Acta Part A Mol. Biomol. Spectrosc. 2018, 210, 315-320. [CrossRef] [PubMed]

4. Yang, S.; Liu, X.; Zeng, X.; Xia, B.; Gu, J.; Luo, S.; Mai, N.; Wei, W. Fabrication of nano-copper/carbon nanotubes/chitosan film by one-step electrodeposition and its sensitive determination of nitrite. Sens. Actuators B Chem. 2010, 145, 762-768. [CrossRef]

5. $\quad$ Ferreira, F.T.S.M.; Mesquita, R.B.R.; Rangel, A.O.S.S. Novel microfluidic paper-based analytical devices ( $\mu$ PADs) for the determination of nitrate and nitrite in human saliva. Talanta 2020, 219, 121183. [CrossRef] [PubMed]

6. Ridnour, L.A.; Sim, J.E.; Hayward, M.A.; Wink, D.A.; Martin, S.M.; Buettner, G.R.; Spitz, D.R. A spectrophotometric method for the direct detection and quantitation of nitric oxide, nitrite, and nitrate in cell culture media. Anal. Biochem. 2000, 281, 223-229. [CrossRef]

7. Miranda, K.M.; Espey, M.G.; Wink, D.A. A rapid, simple spectrophotometric method for simultaneous detection of nitrate and nitrite. Nitric Oxide Biol. Chem. 2001, 5, 62-71. [CrossRef]

8. Kodamatani, H.; Yamazaki, S.; Saito, K.; Tomiyasu, T.; Komatsu, Y. Selective determination method for measurement of nitrite and nitrate in water samples using high-performance liquid chromatography with post-column photochemical reaction and chemiluminescence detection. J. Chromatogr. A 2009, 1216, 3163-3167. [CrossRef] [PubMed]

9. Helaleh, M.I.H.; Korenaga, T. Ion chromatographic method for simultaneous determination of nitrate and nitrite in human saliva. J. Chromatogr. B Biomed. Sci. Appl. 2000, 744, 433-437. [CrossRef]

10. Wu, J.; Wang, X.; Lin, Y.; Zheng, Y.; Lin, J. Peroxynitrous-acid-induced chemiluminescence detection of nitrite based on Micro fl uidic chip. Talanta 2016, 154, 73-79. [CrossRef] [PubMed]

11. Zhao, Z.; Zhang, J.; Wang, W.; Sun, Y.; Hu, J.; Chen, L.; Gong, W. Synthesis and Electrochemical Properties of Co3O4-rGO/CNTs Composites toward Highly Sensitive Nitrite Detection. Appl. Surf. Sci. 2019, 485, 274-282. [CrossRef]

12. Essousi, H.; Barhoumi, H.; Bibani, M.; Ktari, N.; Wendler, F.; Al-Hamry, A.; Kanoun, O. Ion-Imprinted Electrochemical Sensor Based on Copper Nanoparticles-Polyaniline Matrix for Nitrate Detection. J. Sens. 2019, 4257125. [CrossRef]

13. Talbi, M.; Al-Hamry, A.; Rios, P.; Bouhamed, A.; Azzouzi, S.; Paterno, L.G.; Ben, M. Graphite Screen Printed Electrodes Functionalized with AuNPs-PEI for Nitrite Detection. In Proceedings of the International Multi-Conference on Systems, Signals \& Devices (SSD), Istanbul, Turkey, 21-24 March 2019; IEEE: Piscataway, NJ, USA, 2019; 4, pp. 2019-2022.

14. Nasraoui, S.; Al-Hamry, A.; Teixeira, P.R.; Paterno, L.G.; Ali, M.B.; Kanoun, O. Electrochemical sensor for nitrite detection in water samples using flexible laser-induced graphene electrodes functionalized by CNT decorated by Au nanoparticles. J. Electroanal. Chem. 2020, 880, 114893. [CrossRef]

15. Beaver, K.; Dantanarayana, A.; Minteer, S.D. Materials Approaches for Improving Electrochemical Sensor Performance. J. Phys. Chem. B 2021, 125, 11820-11834. [CrossRef] [PubMed]

16. Keçili, R.; Denizli, A. Molecular Imprinting-Based Smart Nanosensors for Pharmaceutical Applications. In Molecular Imprinting for Nanosensors and Other Sensing Applications; Elsevier Inc.: Amsterdam, The Netherlands, 2021; ISBN 9780128221174. [CrossRef]

17. Alam, A.U.; Deen, M.J. Bisphenol A Electrochemical Sensor Using Graphene Oxide and $\beta$-Cyclodextrin-Functionalized MultiWalled Carbon Nanotubes. Anal. Chem. 2020, 92, 5532-5539. [CrossRef]

18. Manikandan, V.S.; Adhikari, B.R.; Chen, A. Nanomaterial based electrochemical sensors for the safety and quality control of food and beverages. Analyst 2018, 143, 4537-4554. [CrossRef]

19. Andreoli, E.; Annibaldi, V.; Rooney, D.A.; Liao, K.S.; Alley, N.J.; Curran, S.A.; Breslin, C.B. Electrochemical conversion of copper-based hierarchical micro/nanostructures to copper metal nanoparticles and their testing in nitrate sensing. Electroanalysis 2011, 23, 2164-2173. [CrossRef]

20. Rastogi, P.K.; Ganesan, V.; Krishnamoorthi, S. A promising electrochemical sensing platform based on a silver nanoparticles decorated copolymer for sensitive nitrite determination. J. Mater. Chem. A 2014, 2, 933-943. [CrossRef]

21. Bagheri, H.; Hajian, A.; Rezaei, M.; Shirzadmehr, A. Composite of Cu metal nanoparticles-multiwall carbon nanotubes-reduced graphene oxide as a novel and high performance platform of the electrochemical sensor for simultaneous determination of nitrite and nitrate. J. Hazard. Mater. 2017, 324, 762-772. [CrossRef] [PubMed]

22. Abdel Hameed, R.M.; Medany, S.S. Sensitive nitrite detection at core-shell structured Cu@Pt nanoparticles supported on graphene. Appl. Surf. Sci. 2018, 458, 252-263. [CrossRef]

23. Chauhan, N.; Pundir, C.S. An amperometric biosensor based on acetylcholinesterase immobilized onto iron oxide nanoparticles/multi-walled carbon nanotubes modified gold electrode for measurement of organophosphorus insecticides. Anal. Chim. Acta 2011, 701, 66-74. [CrossRef] [PubMed]

24. Guo, S.; Wang, E. Synthesis and electrochemical applications of gold nanoparticles. Anal. Chim. Acta 2007, 598, 181-192. [CrossRef] [PubMed]

25. Daniel, M.; Astruc, D. Gold Nanoparticles: Assembly, Supramolecular Chemistry, Quantum-Size-Related Properties, and Applications toward Biology, Catalysis, and Nanotechnology. Chem. Rev. 2004, 104, 293-346. [CrossRef] 
26. Afkhami, A.; Soltani-Felehgari, F.; Madrakian, T.; Ghaedi, H. Surface decoration of multi-walled carbon nanotubes modified carbon paste electrode with gold nanoparticles for electro-oxidation and sensitive determination of nitrite. Biosens. Bioelectron. 2014, 51, 379-385. [CrossRef]

27. Rao, H.; Liu, Y.; Zhong, J.; Zhang, Z.; Zhao, X.; Liu, X.; Jiang, Y.; Zou, P.; Wang, X.; Wang, Y. Gold Nanoparticle/Chitosan@N,S Co-doped Multiwalled Carbon Nanotubes Sensor: Fabrication, Characterization, and Electrochemical Detection of Catechol and Nitrite. ACS Sustain. Chem. Eng. 2017, 5, 10926-10939. [CrossRef]

28. Chen, H.; Yang, T.; Liu, F.; Li, W. Electrodeposition of gold nanoparticles on Cu-based metal-organic framework for the electrochemical detection of nitrite. Sens. Actuators B Chem. 2018, 286, 401-407. [CrossRef]

29. Kang, S.; Zhang, H.; Wang, G.; Zhang, Y.; Zhao, H.; Zhou, H.; Cai, W. Highly sensitive detection of nitrite by using gold nanoparticles-decorated $\alpha$-Fe2O3 nanorod arrays as self-supporting photo-electrodes. Inorg. Chem. Front. 2019, 6, $1432-1441$. [CrossRef]

30. Yu, H.; Li, R.; Song, K.-1. Amperometric determination of nitrite by using a nanocomposite prepared from gold nanoparticles, reduced graphene oxide and multi-walled carbon nanotubes. Microchim. Acta 2019, 186, 624. [CrossRef] [PubMed]

31. Balasubramanian, P.; Balamurugan, T.S.T.; Chen, S. Highly Sensitive Electrochemical Detection of Nitrite Ions in Food Samples via $\beta$-Cyclodextrin Capped Gold Nanoparticles Film Modified Glassy Carbon Electrode. J. Electrochem. Soc. 2017, 164, 715-722. [CrossRef]

32. Li, X.; Zou, N.; Wang, Z.; Sun, Y.; Li, H.; Gao, C.; Wang, T.; Wang, X. An electrochemical sensor for determination of nitrite based on Au nanoparticles decorated MoS2 nanosheets. Chem. Pap. 2020, 74, 441-449. [CrossRef]

33. Teixeira, P.R.; Santos, M.S.; Silva, A.L.G.; Báo, S.N.; Azevedo, R.B.; Sales, M.J.A.; Paterno, L.G. Photochemically-Assisted Synthesis of Non-toxic and Biocompatible Gold Nanoparticles. Colloids Surf. B Biointerfaces 2016, 148, 317-323. [CrossRef]

34. Borkovec, M.; Koper, G.J.M. Proton Binding Characteristics of Branched Polyelectrolytes. Macromolecules 1997, 30, 2151-2158. [CrossRef]

35. Davey, W.P. Precision measurements of the lattice constants of twelve common metals. Phys. Rev. 1925, 25, 538. [CrossRef]

36. Broder, T.L.; Silvester, D.S.; Aldous, L.; Hardacre, C.; Compton, R.G. Electrochemical oxidation of nitrite and the oxidation and reduction of NO2 in the room temperature ionic liquid [C2mim][NTf 2]. J. Phys. Chem. B 2007, 111, 7778-7785. [CrossRef]

37. Sahoo, S.; Sahoo, P.K.; Sharma, A.; Satpati, A.K. Interfacial polymerized RGO/MnFe2O4/polyaniline fibrous nanocomposite supported glassy carbon electrode for selective and ultrasensitive detection of nitrite. Sens. Actuators B Chem. 2020, 309, 127763. [CrossRef]

38. Keita, B.; Essaadi, K.; Nadjo, L.; Desmadril, M. Rate-limiting one-electron transfer in the oxidation of NADH by polyoxometalates. Chem. Phys. Lett. 1995, 237, 411-418. [CrossRef]

39. Piela, B.; Piela, P.; Wronaa, P.K. Oxidation of nitrite on solid electrodes: II. Determination of the reaction mechanism on surfaces covered by an oxide layer. J. Electrochem. Soc. 2002, 149, 357-366. [CrossRef]

40. Jian, J.M.; Fu, L.; Ji, J.; Lin, L.; Guo, X.; Ren, T.L. Electrochemically reduced graphene oxide/gold nanoparticles composite modified screen-printed carbon electrode for effective electrocatalytic analysis of nitrite in foods. Sens. Actuators B Chem. 2018 262, 125-136. [CrossRef]

41. Han, Y.; Zhang, R.; Dong, C.; Cheng, F.; Guo, Y. Sensitive electrochemical sensor for nitrite ions based on rose-like AuNPs/MoS2/ graphene composite. Biosens. Bioelectron. 2019, 142, 111529. [CrossRef] [PubMed]

42. He, B.; Yan, D. Au/ERGO nanoparticles supported on Cu-based metal-organic framework as a novel sensor for sensitive determination of nitrite. Food Control 2019, 103, 70-77. [CrossRef]

43. Losada, J.; García Armada, M.P.; García, E.; Casado, C.M.; Alonso, B. Electrochemical preparation of gold nanoparticles on ferrocenyl-dendrimer film modified electrodes and their application for the electrocatalytic oxidation and amperometric detection of nitrite. J. Electroanal. Chem. 2017, 788, 14-22. [CrossRef]

44. Rostami, M.; Abdi, G.; Habib, S.; Alizadeh, A. Nanocomposite of magnetic nanoparticles/graphene oxide decorated with acetic acid moieties on glassy carbon electrode: A facile method to detect nitrite concentration. J. Electroanal. Chem. 2019, 847, 113239. [CrossRef] 